\title{
The Influence of Complex Subway Station Construction on High Retaining Walls and Appropriate Countermeasures
}

\author{
Kai Wang, ${ }^{1}$ Zhaoping Li ${ }^{D},{ }^{1}$ Xuezhao Xu, ${ }^{1}$ Leilei Shi, ${ }^{2}$ and Fanbo Zhang $^{1}$ \\ ${ }^{1}$ School of Civil Engineering, Beijing Jiaotong University, Beijing 100044, China \\ ${ }^{2}$ Beijing No. 4 Municipal Construction Engineering Co., Ltd., Beijing 100176, China \\ Correspondence should be addressed to Zhaoping Li; zhpli@bjtu.edu.cn
}

Received 31 May 2020; Revised 7 July 2020; Accepted 13 July 2020; Published 31 July 2020

Academic Editor: Wen-Chieh Cheng

Copyright (c) 2020 Kai Wang et al. This is an open access article distributed under the Creative Commons Attribution License, which permits unrestricted use, distribution, and reproduction in any medium, provided the original work is properly cited.

Anzhen Bridge Station of Beijing metro line 12, which adopts a separated-island platform constructed by the undermining method, passes along the retaining wall of the North Third Ring Road. A numerical simulation method is adopted to study the deformation laws of the retaining wall under the influence of station construction. The simulation data show that the affected retaining wall will have large settlement and tilt, and countermeasures must be taken. Four countermeasures are formulated, and their control effects are analyzed. The calculation results show that the combination of anchor cables and waist beams can effectively control the tilt of the retaining wall, but the control effect on the absolute settlement is not obvious. The control effect of isolation piles is better than that of foundation grouting. The joint control method of anchor cables combined with waist beams, isolation piles, and deep hole grouting makes the deformation meet the target, and according to this measure, a concept of joint control aiming at the influence of the "source," "propagation," and "object" is proposed, which can provide a reference for similar projects with a great difficulty in deformation control.

\section{Introduction}

In concentrated areas, subway lines are usually laid along a city's main road, so the subway tunnel or station underpasses the road frequently. In overpass sections, retaining walls are often installed, and subway construction will not only affect road safety [1-3], but also threaten the stability and safety of the retaining walls. At present, there have been many studies on the stability of retaining walls, including the stability of retaining walls under static loads [4-6], the dynamic response of retaining walls [7-11], the behavior of retaining walls affected by deep excavation $[12,13]$, and the time-dependent behavior of piles and retaining walls as a result of excavationinduced soil movement [14]. These studies have made many achievements in terms of the stability of retaining walls. However, the response of a road retaining wall with a shallow foundation under the influence of underground excavation has not been fully studied. According to the in-situ settlement laws of the retaining wall embankment, $\mathrm{Ma}$ et al. [15] summarized the experiences on real-time adjustment of shield construction parameters and comprehensive use of grouting. Liu [16] analyzed the settlement laws of the highway retaining wall under the influence of tunnel construction by numerical simulation. The above research only concerns the settlement of the retaining wall. Sun [17] analyzed the settlement and tilt laws of the road retaining walls affected by shallow buried tunnels. However, the influence of station construction is more complicated than that of tunnel and there is little literature on the response of the road retaining wall under the influence of subway station construction.

According to previous research on the influence of underground construction on soil movement, station construction has the following main effects on retaining walls.

1.1. Absolute Subsidence. Soil excavation causes stratum settlement [18-20]. A retaining wall will settle with the ground if its foundation is in the settlement area. The resulting settlement is absolute subsidence. In this project, the minimum horizontal distance between the main body and the retaining wall foundation is only $1.05 \mathrm{~m}$. Too much absolute settlement will affect the stability of the pavement structure, resulting in a poor connection between the pavement and the bridge deck and endangering traffic safety. 
1.2. Differential Settlement. Differential settlement refers to nonuniform settlement along retaining walls, the magnitude of which is the difference in the vertical displacement between two measured points. The reasons for differential settlement are complicated and include the complexity of station construction processes, the inhomogeneity of the strata and the filling, and the construction of connecting channels. Excessive differential settlement will lead to cracks in the retaining wall, which will seriously destabilize the retaining wall and lead to accidents such as soil filling collapse and road damage.

1.3. Tilt Deformation. The closer a retaining wall is to the centerline of the main structure, the greater the surface settlement caused by construction [21-23]. Therefore, a difference in the lateral settlement of the retaining wall foundation will cause the retaining wall to tilt and even collapse in serious cases.

However, the above deformation laws and effective control measures are currently unclear.

The construction of Anzhen Bridge Station of Beijing metro line 12 will affect the retaining walls of the North Third Ring Road. Because the station adopts a separatedisland platform constructed by the undermining method, the construction of the main part of the station and the two connecting aisles will have a superimposed impact on the retaining wall, threatening the stability and safety of the retaining wall. Based on this background, this paper analyzed the deformation laws of retaining walls under the influence of station construction and proposed effective control measures and control concepts.

\section{Project Overview}

Anzhen Bridge Station is at the intersection of An-Ding Road and the North Third Ring Road in an east-west alignment along the North Third Ring Road. It is a doubledeck separated-island platform station constructed by the PBA (Pile-Beam-Arc) method. The depth of the standard section is $14.9 \mathrm{~m}$. There are two overpasses named Anzhen East Bridge and Anzhen West Bridge over Andingmenwai Street running from east to west along the North Third Ring Road. There are three sections of retaining walls: one to the east of Anzhen East Bridge, one between the two bridges, and one to the west of Anzhen West Bridge. The retaining wall is a counterfort type with a maximum height of $5.57 \mathrm{~m}$. There are 20 retaining walls between the two bridges, and every five retaining walls share a common foundation. A deformation joint of $20 \mathrm{~mm}$ is set between the adjacent retaining walls. The Anzhen East Bridge and the walls are depicted in Figure 1. A plan sketch of the station and the retaining walls is shown in Figure 2. The vertical positions of the connecting aisles and retaining wall and of the main structure of the station and retaining wall are shown in Figures 3 and 4, respectively.

Because the height of the retaining wall between the East and West Anzhen Bridges is large, and it is influenced by the construction of the main structure of the station and the

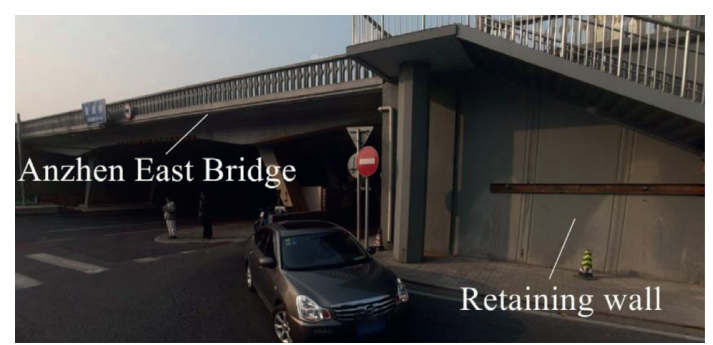

Figure 1: Image of Anzhen East Bridge and the retaining walls.

connection channels, this section of retaining wall is chosen as the research object.

The control indexes of retaining wall deformation were formulated by comprehensively considering the structural features; design calculation results and national standard named the "Code for Monitoring Measurement of Urban Rail Transit Engineering" (GB 50911-2013) are considered comprehensively. The control indexes of retaining wall deformation are as follows:

(1) Maximum absolute settlement of the retaining wall is $15 \mathrm{~mm}$

(2) Maximum differential settlement of adjacent retaining walls is $8 \mathrm{~mm}$

(3) Maximum tilt deformation of the retaining wall is $1 \%$

\section{Calculation of the Stability of the Retaining Wall Affected by Station Construction}

3.1. Calculation Model. The overall model size should consider the boundary effect. According to the actual relationship between the position of retaining wall and that of the station structure, the calculation model shown in Figure 5 should be established. To better demonstrate the spatial position relationship of each structure, the spatial positions of the station structures and the retaining wall are shown in Figure 6.

The stratum size in the model is $x \times y \times z=140 \mathrm{~m} \times 50 \mathrm{~m} \times 60 \mathrm{~m}$. There are six layers. From top to bottom, there are miscellaneous fill, silt, silty clay, silty clay and clay, silty-fine sand, and pebbles. The width of a single retaining wall is $2 \mathrm{~m}$, and the width of a deformation joint is $2 \mathrm{~cm}$. There are 19 deformation joints in 20 retaining walls. Therefore, the length of the retaining wall in the model is $y=40.38 \mathrm{~m}$. The size of the retaining wall fill is $x \times y \times z=44.1 \mathrm{~m} \times 40.38 \mathrm{~m} \times 5.57 \mathrm{~m}$.

Every five retaining walls share a common foundation, so there are three deformation joints in twenty retaining walls. These deformation joints are designated as \#1, \#2, and \#3 from west to east. Four measurement points are arranged for each deformation joint, which are on both sides of the wall top and on both sides of the wall bottom, so 12 measurement points are arranged for the 3 deformation joints.

Because the north and south retaining walls are symmetrically arranged with the station structure and the deformation laws are similar, only the north retaining wall is selected 


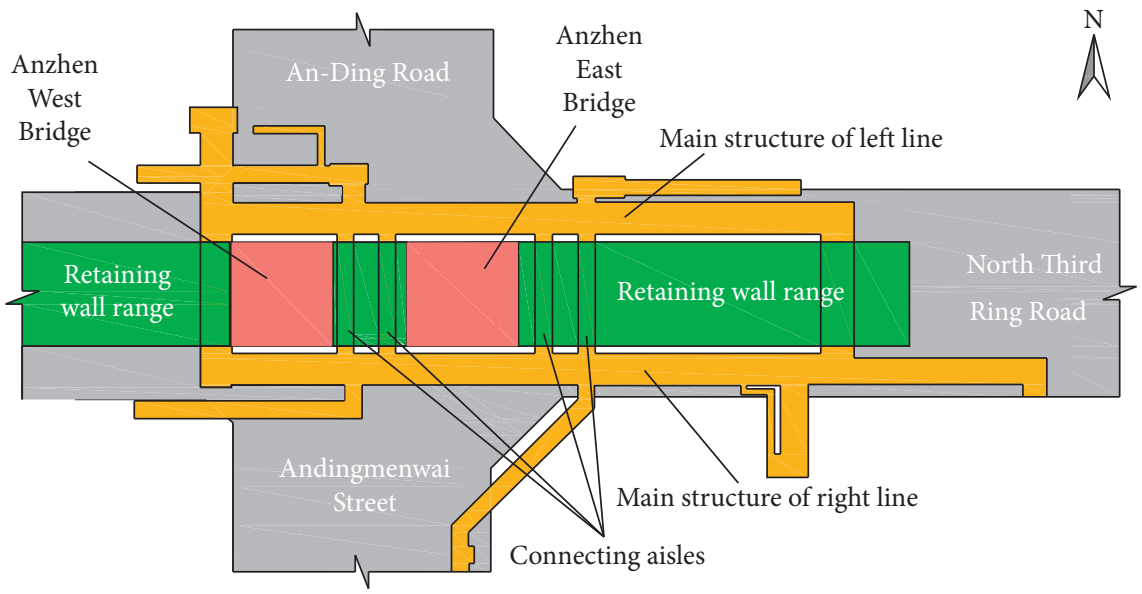

FIgURE 2: Plan sketch of the station and the retaining wall.

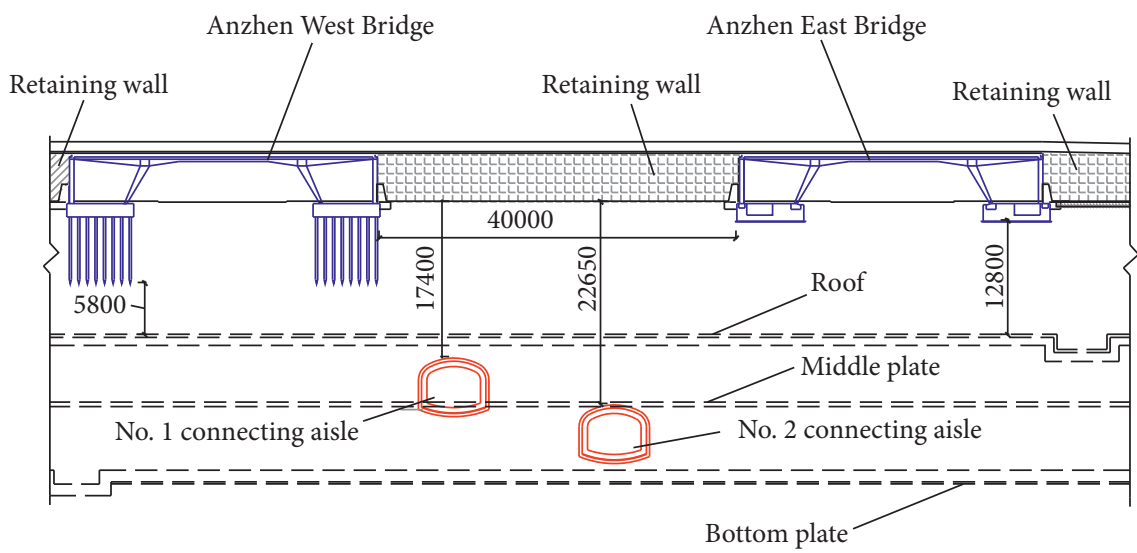

FIgURE 3: Vertical positions of the connecting aisles and the retaining wall (unit: $\mathrm{mm}$ ).

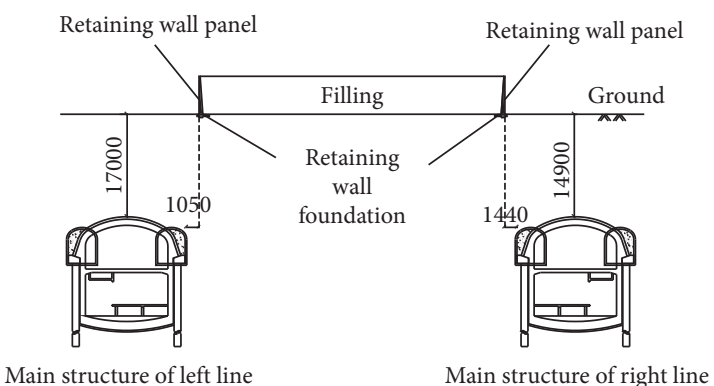

FIGURE 4: Vertical positions of the main structure of the station and the retaining wall (unit: $\mathrm{mm}$ ).

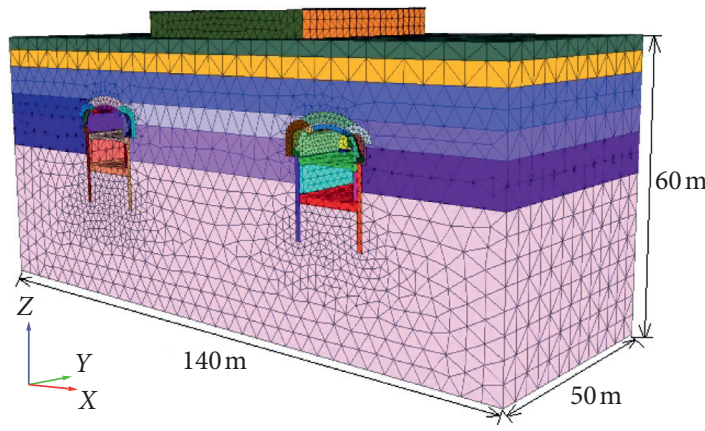

FIGURE 5: Overall model.

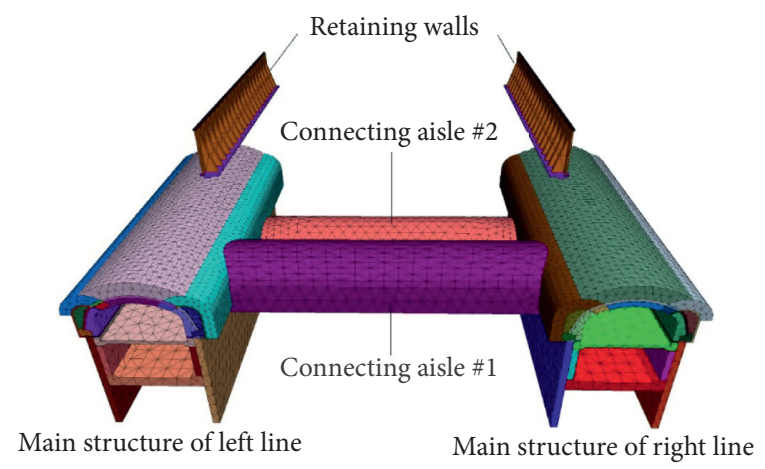

FIGURE 6: Spatial positions of the station structures and the retaining wall.

as the research object. The number and corresponding location of each measurement point are shown in Figure 7.

3.2. Calculating Parameters. The concrete structures of the station adopt the linear elastic constitutive model, and the soil materials adopt the Mohr-Coulomb constitutive model [24]. To ensure the accuracy of the simulation results, the numerical parameters of the soil layers were obtained from the geological 


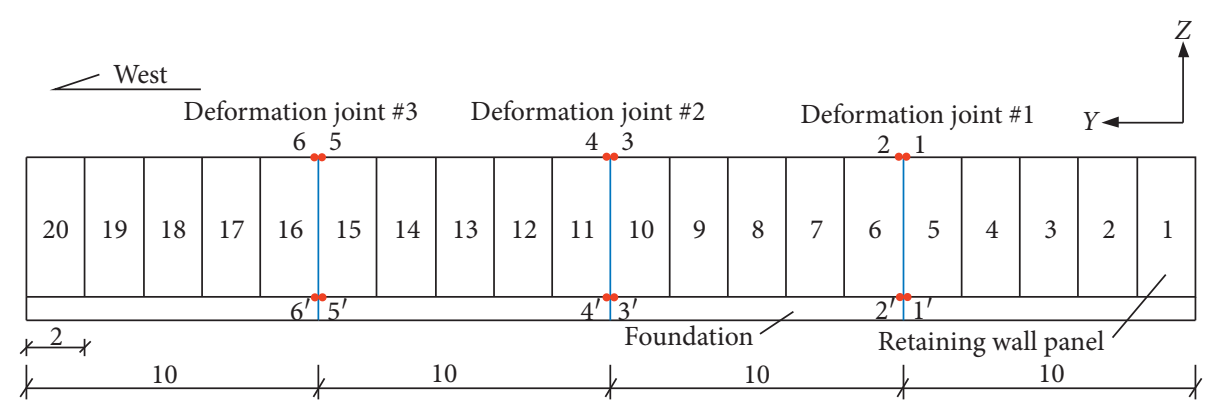

FIgURE 7: Schematic diagram of measurement point arrangement (unit: m).

TABLe 1: Physical and mechanical parameters of the strata.

\begin{tabular}{|c|c|c|c|c|c|c|}
\hline Layers & $\begin{array}{c}\text { Thickness } \\
(\mathrm{m})\end{array}$ & $\begin{array}{l}\text { Unit weight }(\mathrm{kN} / \\
\left.\mathrm{m}^{3}\right)\end{array}$ & $\begin{array}{c}\text { Cohesive force } \\
(\mathrm{kPa})\end{array}$ & $\begin{array}{c}\text { Internal friction } \\
\text { angle }\left({ }^{\circ}\right)\end{array}$ & $\begin{array}{l}\text { Poisson's } \\
\text { ratio }\end{array}$ & $\begin{array}{l}\text { Modulus of elasticity } \\
(\mathrm{MPa})\end{array}$ \\
\hline Retaining wall fill & 3.0 & 17.0 & 5 & 10 & 0.35 & 5 \\
\hline Miscellaneous fill & 3.0 & 17.0 & 5 & 10 & 0.35 & 5 \\
\hline Silt & 4.2 & 19.3 & 18 & 25.7 & 0.30 & 8 \\
\hline Silty clay & 6.8 & 19.7 & 28 & 16 & 0.30 & 12 \\
\hline Silty clay and clay & 4.8 & 19.7 & 32 & 17 & 0.30 & 14 \\
\hline Silty-fine sand & 8.2 & 20.2 & 15 & 40 & 0.25 & 75 \\
\hline Pebble & 33.0 & 21.2 & 0 & 45 & 0.20 & 120 \\
\hline $\begin{array}{l}\text { Grouting reinforced } \\
\text { body }\end{array}$ & - & 22 & 40 & 18 & 0.25 & 50 \\
\hline
\end{tabular}

Table 2: Physical and mechanical parameters of the structures.

\begin{tabular}{llccc}
\hline Constructions & Materials & Unit weight $\left(\mathrm{kN} / \mathrm{m}^{3}\right)$ & Cohesive force $(\mathrm{GPa})$ & 31.5 \\
\hline Retaining wall panel & C35 concrete & 24.5 & 30 & Poisson's ratio \\
Retaining wall foundation & C30 concrete & 24.5 & 32.5 & 0.25 \\
Railing base & C40 concrete & 25 & 28 & 0.25 \\
Initial support & C25 concrete & 24 & 30 & 0.24 \\
Pile & C30 concrete & 24.5 & 30 & 0.2 \\
Crown beam & C30 concrete & 24.5 & 25.5 & 0.25 \\
Pilot tunnel filling & C20 concrete & 24 & 32.5 & 0.25 \\
Secondary lining & C40 concrete & 25 & 0.25 \\
\hline
\end{tabular}

investigation report and laboratory tests. To reflect the actual soil-wall interaction behavior, interface elements are used in finite element analysis to simulate sliding between two different materials [25]. The mechanical parameters of the strata and structures are shown in Tables 1 and 2, respectively.

\subsection{Calculation Results}

3.3.1. Absolute Settlement of the Retaining Wall. The absolute settlement of the top of the wall is affected by the tilt deformation of the retaining wall, so an additional settlement value $h(1-\cos \theta)$ is added (where $h$ is the height of the wall, and $\theta$ is the tilt deformation angle of the retaining wall). Therefore, the displacement data of measurement points $1^{\prime}-6^{\prime}$ in the $Z$-direction at the bottom of the wall are processed to obtain the settlement curves of the entire construction process, as shown in Figure 8 (the construction sequence of the PBA method is pilot tunnels, side piling, crown beam, arch, middle plate, floor, and side walls. Only the main construction procedures are shown in Figure 8, and the construction of the connecting aisles is added).
Figure 8 shows the following:

(1) The construction of both the main structure and the connecting aisle will cause the settlement of the retaining wall. The calculated data show that the settlement caused by the construction of the main structure and the construction of the connecting aisle account for approximately $80 \%$ and $20 \%$ of the final settlement of the retaining wall, respectively

(2) In the constructions of the pilot tunnels and arch, the curves fall quickly, indicating that these two stages have a great influence on the retaining wall

(3) Among measurement points $1^{\prime}-6^{\prime}$, the maximum settlement is $56.78 \mathrm{~mm}$ at measurement points $1^{\prime}$, and the minimum settlement is $44.19 \mathrm{~mm}$ at measurement points $5^{\prime}$, both of which exceed the settlement index of $15 \mathrm{~mm}$.

According to the settlement value of the midpoint at the bottom of each retaining wall, the final settlement of each retaining wall bottom is shown in Figure 9 (the westernmost 


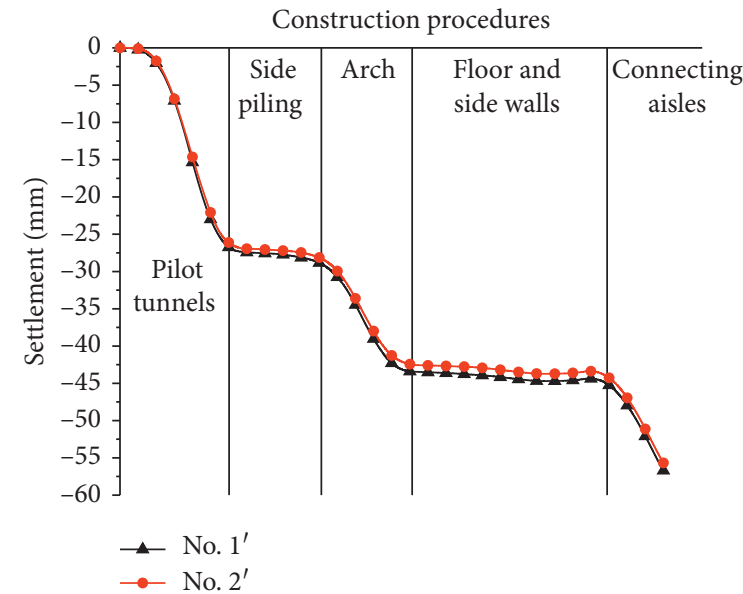

(a)

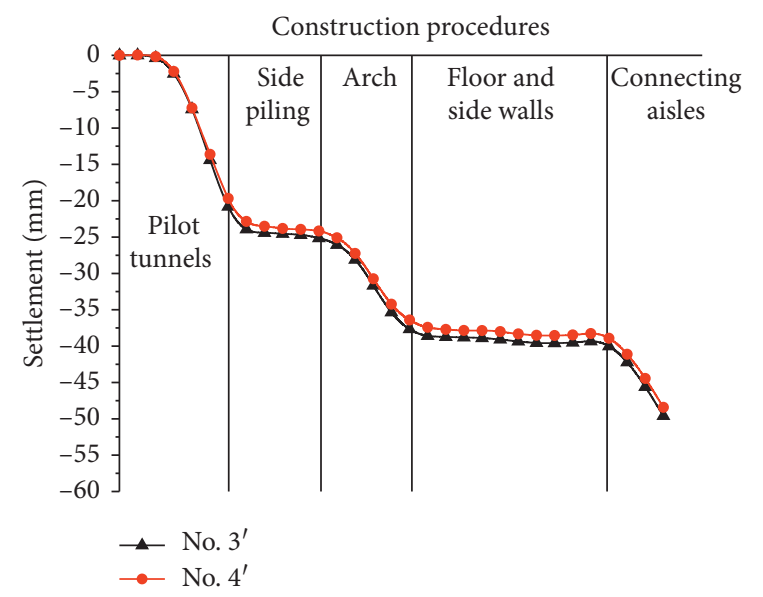

(b)

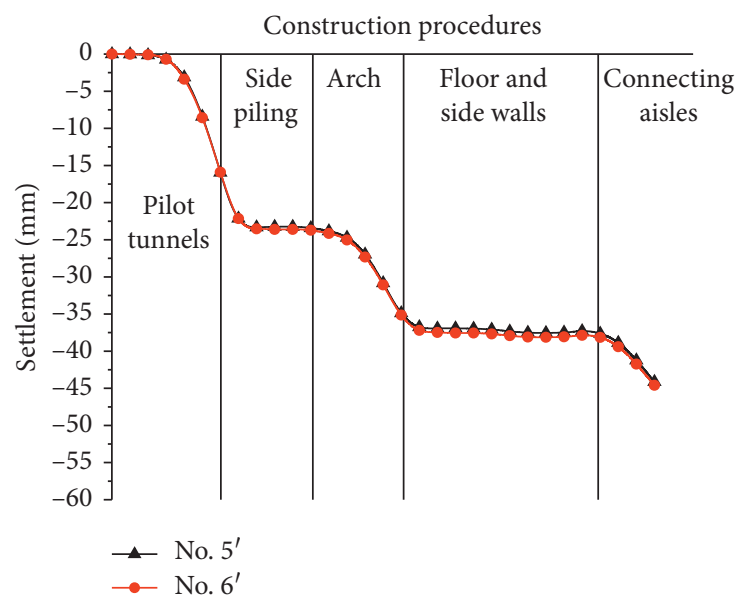

(c)

Figure 8: (a) Diachronic settlement curves of the measurement points at the wall bottom in the deformation joint \#1. (b) Diachronic settlement curves of the measurement points at the wall bottom in the deformation joint \#2. (c) Diachronic settlement curves of the measurement points at the wall bottom in the deformation joint \#3.

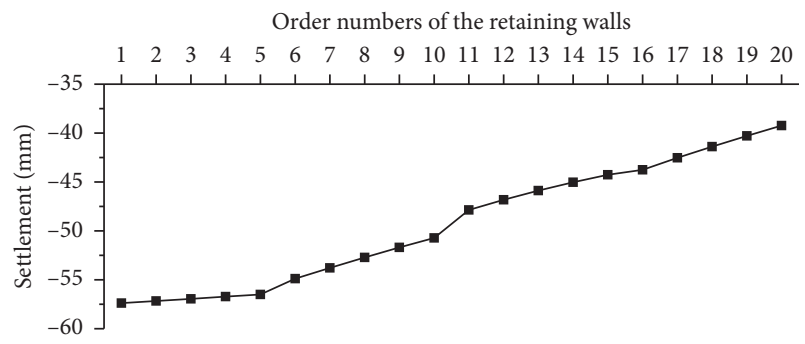

FIGURE 9: Wall bottom final settlement of each retaining wall.

retaining wall is numbered 1 , and the numbers increase from west to east).

As shown in Figure 9, under the influence of station construction, the final settlement of the retaining wall presents a trend of "high in the east and low in the west." The maximum settlement is in retaining wall No. 1 with a settlement value of $57.39 \mathrm{~mm}$, and the minimum settlement is in retaining wall No. 20 with a settlement value of $39.23 \mathrm{~mm}$. The difference between the two is $18.16 \mathrm{~mm}$. The reason why the retaining wall is high in the east and low in the west is that the west retaining wall is affected by the superposition of the construction of the main structure of the station and the construction of connecting aisle \#1. This influence gradually decreases from the centerline of connecting aisle \#1 to both sides, so the settlement value decreases gradually from west to east. This phenomenon can be more intuitively illustrated from the settlement cloud map vertically split along the retaining wall, as shown in Figure 10.

3.3.2. Differential Settlement of the Retaining Wall. By subtracting the settlement value of measurement point No. $1^{\prime}$ from the settlement value of measurement point No. $2^{\prime}$, the difference of each time is obtained to form the diachronic differential settlement curve of deformation joint \#1, and the differential settlement curves of deformation joints \#2 and \#3 are also obtained in a similar way, as shown in Figure 11 (the positive and negative signs of the differential settlement value in Figure 11 represent the height difference between the left and right sides of the deformation joint, not the size). 


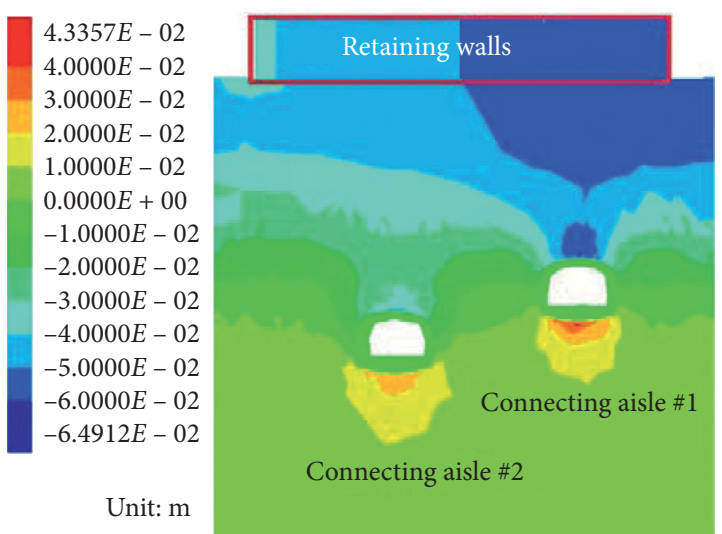

Figure 10: Settlement cloud map under the influence of the construction of the connecting aisles.

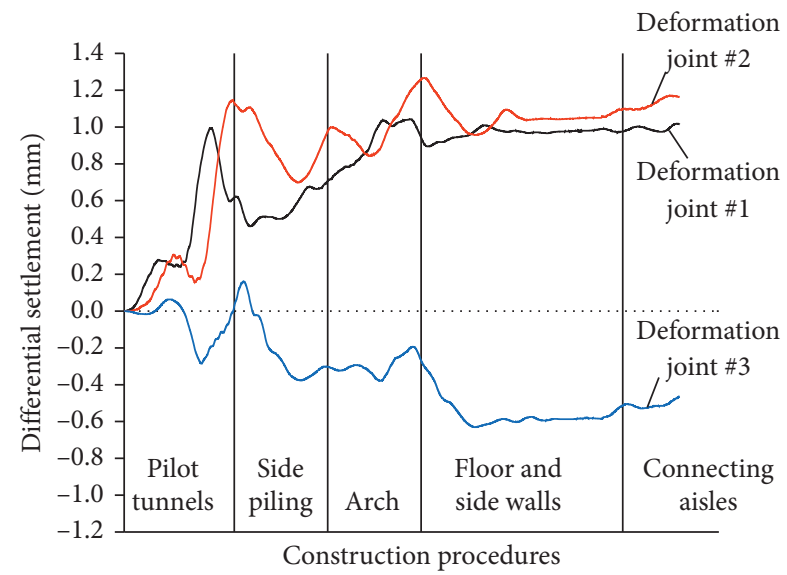

FIGURE 11: Diachronic differential settlement curve of each deformation joint.

As shown in Figure 11, the maximum differential settlement does not occur at the end of construction but rather during construction. The maximum differential settlements of deformation joints \#1, \#2, and \#3 are $1.04 \mathrm{~mm}, 1.27 \mathrm{~mm}$, and $0.63 \mathrm{~mm}$, respectively, all of which are less than the index value of $8 \mathrm{~mm}$. Therefore, the station construction has little influence on the differential settlement of the retaining wall, so the differential settlement of the retaining wall can be regarded as a nonkey control index when formulating protection measures.

3.3.3. Tilt Rate of the Retaining Wall. The tilt rate of the retaining wall is the ratio of the horizontal displacement difference between the wall top and the wall bottom to the height of the wall-that is,

$$
t=\left[\frac{\left(x-x^{\prime}\right)}{h}\right] \times 1000 \%,
$$

where $t$ is the tilt rate of the retaining wall, $x$ is the horizontal displacement of the wall top, $x^{\prime}$ is the horizontal displacement of the wall bottom, and $h$ is the height of the wall. According to the calculation results of the tilt rate, the changing curves of the tilt rate with construction progress for the six measurement lines from $1-1^{\prime}$ to $6-6^{\prime}$ are obtained, as shown in Figure 12 (the positive and negative signs of the tilt rate in the figure represent the tilt direction, not its size).

In the constructions of the pilot tunnels and arch, the curves show obvious peak values, indicating once again that these two stages have a great influence on the retaining wall. The maximum tilt rates of the measurement lines from $1-1^{\prime}$ to $6-6^{\prime}$ are $4.13 \%$ o, 3.62\%o, 3.62\%o, 3.29\%o, 3.16\%o, and 3.06\%o, respectively, all of which exceed the index value of $1 \%$.

The simulated data show that the final tilt rate of each retaining wall decreases gradually from west to east. To better reflect this phenomenon, the final tilt rate of each retaining wall is shown in Figure 13 (the westernmost retaining wall is numbered 1 , and the numbers increase from west to east).

As shown in Figure 13, due to the construction of connecting aisle \#1, the tilt rate of the retaining wall shows a trend of "small in the east and large in the west," corresponding to the settlement deformation of "high in the east and low in the west," and the final tilt rates of all 20 retaining walls exceed the index.

The final tilt rate curve of the retaining wall from west to east presents a "step-down" shape comprising four "steps," and the dividing line between adjacent steps is the position of the deformation joint of the retaining wall foundation. The tilt rate of the five retaining walls sharing one foundation is at the same level, which indicates that the retaining wall foundation features an antitilt ability for the panels.

\section{Deformation Control Measures for the Retaining Wall}

4.1. Formulation of the Control Measures. After the above analysis, the absolute settlement and the tilt of the affected retaining wall both exceed the index values, so corresponding control measures must be taken to ensure safety. According to the conditions of this project, several countermeasures such as anchor cables with waist beams, foundation grouting, isolation piles, and deep hole grouting inside the tunnel are proposed to control the retaining wall deformation.

4.1.1. Anchor Cables with Waist Beams. The retaining walls are connected by waist beams to form a whole, and the anchor cables penetrate the waist beams and are set inwards. The length of the anchor cable is $11.5 \mathrm{~m}$; the length of the free section is $5 \mathrm{~m}$, the length of the anchorage section is $6.5 \mathrm{~m}$, and the inclination angle is $15^{\circ}$ downward. One row of anchor cables is set with 10 cables. To analyze the control effect of the anchor cables with waist beams, two cases are arranged: one row of anchor cables and two rows of anchor cables, as shown in Figure 14.

4.1.2. Foundation Grouting. The grouting position is directly below the retaining wall foundation, and the range is $4.3 \mathrm{~m} \times 42 \mathrm{~m} \times 3 \mathrm{~m}$. When simulating, the stratum parameters after grouting are consistent with those of the advanced 


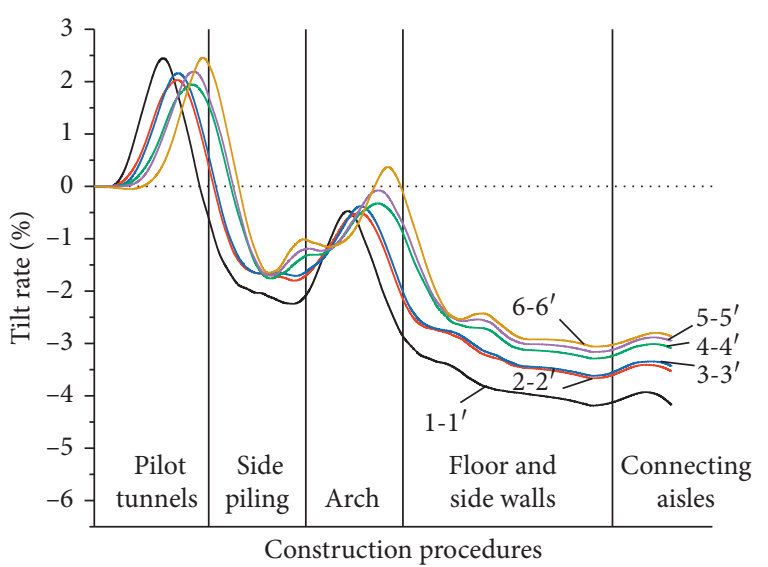

FIgURE 12: Changing curves of the tilt rate.

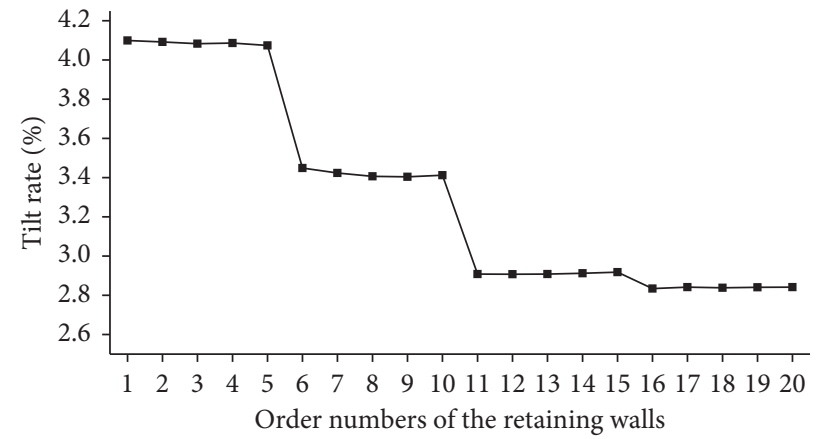

Figure 13: Final tilt rate of each retaining wall.

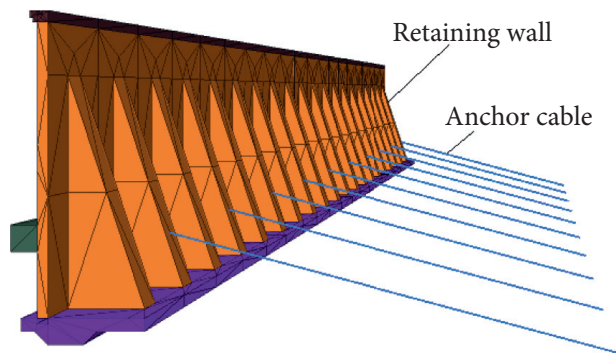

(a)

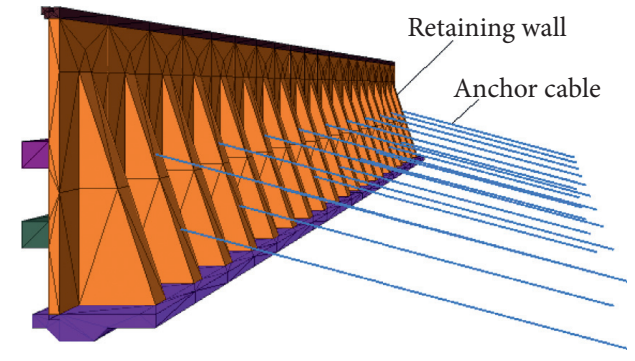

(b)

Figure 14: Anchor cable + waist beam control measure. (a) A row of anchor cables. (b) Two rows of anchor cables.

small pipe grouting. A sketch of the foundation grouting is shown in Figure 15.

4.1.3. Isolation Piles. The isolation pile is in the form of a composite anchor pile, which is designed to bear the bending moment and shear caused by soil movements and is arranged between the main structure of the station and the retaining wall in three rows with a diameter of $0.15 \mathrm{~m}$, an interval of $0.8 \mathrm{~m}$, a row spacing of $1 \mathrm{~m}$, a length of $27 \mathrm{~m}$, and a setting angle of $17^{\circ}$. Based on the principle of equivalent stiffness, the isolated pile is simplified into a continuous structure for simulation. The model diagram is shown in Figure 16.

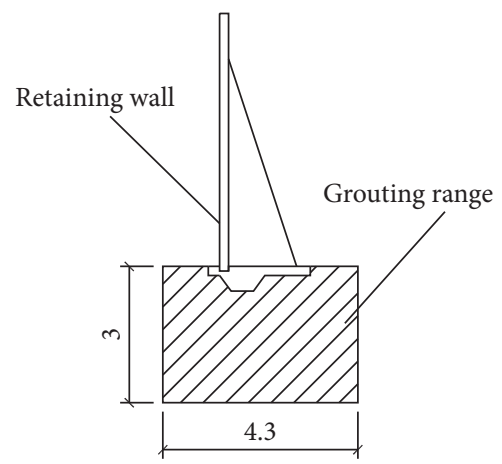

Figure 15: Sketch of the foundation grouting (unit: $\mathrm{m}$ ). 


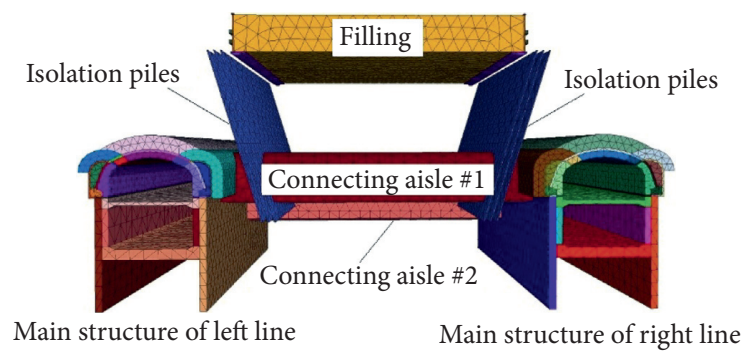

Figure 16: Model diagram of the isolation piles.

4.1.4. Deep Hole Grouting inside the Tunnel. Before the excavation of the main structure of the station, deep hole grouting should be carried out to reinforce the soil in front of the tunnel face. The grouting range is $1.5 \mathrm{~m}$ outside and $0.5 \mathrm{~m}$ inside the excavation contour. The grouting section diagram is shown in Figure 17.

The protective effect of each measure is analyzed below. Because the differential settlement of the retaining wall under the condition of no measures meets the index requirement, analyzing the differential settlement of the retaining wall under various measures is not necessary.

\subsection{Protection Effect of Anchor Cables with Waist Beams}

4.2.1. Control Effect on the Absolute Settlement. According to the settlement value of the midpoint at the bottom of each retaining wall, the final settlement curves of 20 retaining walls under the condition of one row of anchor cables and two rows of anchor cables are compared with the settlement curves without measures, as shown in Figure 18.

Figure 18 shows that the final settlement curves of one row of anchor cables and two rows of anchor cables almost coincide, indicating that there is no significant difference in the control of the absolute settlement between them. The maximum settlement value of one row of anchor cables is $55.34 \mathrm{~mm}$, and the maximum settlement value of two rows of anchor cables is $55.43 \mathrm{~mm}$. Compared with the situation without measures, the settlement value is reduced by $2.04 \mathrm{~mm}$ and $1.95 \mathrm{~mm}$, respectively, so the absolute settlement control effect is not obvious.

4.2.2. Control Effect on Tilt Deformation. The final tilt rate curves of the retaining wall under the two conditions of one row of anchor cables and two rows of anchor cables are compared with those without measures, as shown in Figure 19.

As shown in Figure 19, the maximum tilt rate of the retaining wall with one row of anchor cables is $2.08 \%$, which is $49.27 \%$ lower than that of the retaining wall without measures. The maximum tilt rate of the retaining wall with two rows of anchor cables is $1.31 \%$, which is $68.05 \%$ lower than the maximum tilt rate of the retaining wall without measures. Therefore, the use of anchor cables with waist beams has a significant control effect on the tilt of the retaining wall, but the tilt rate still exceeds the requirements of the index.

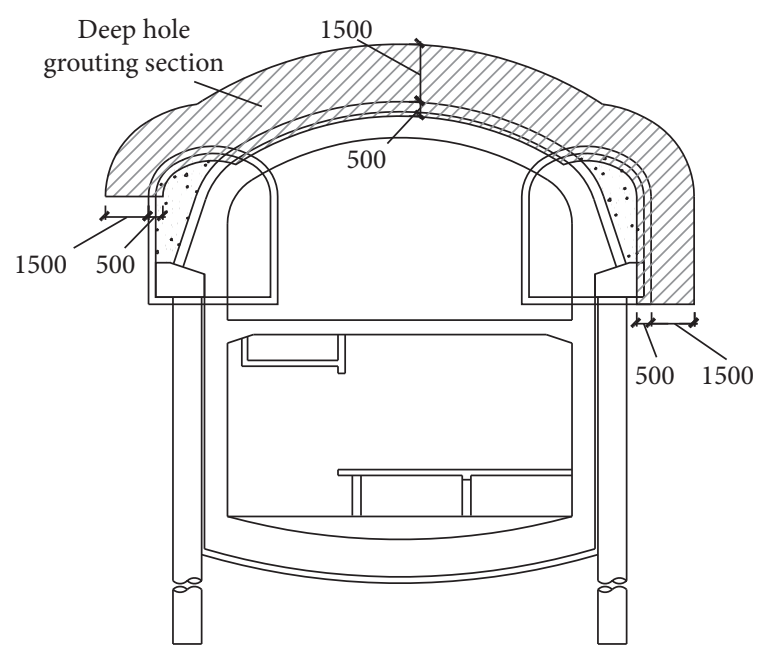

FIGURE 17: Grouting section diagram (unit: mm).

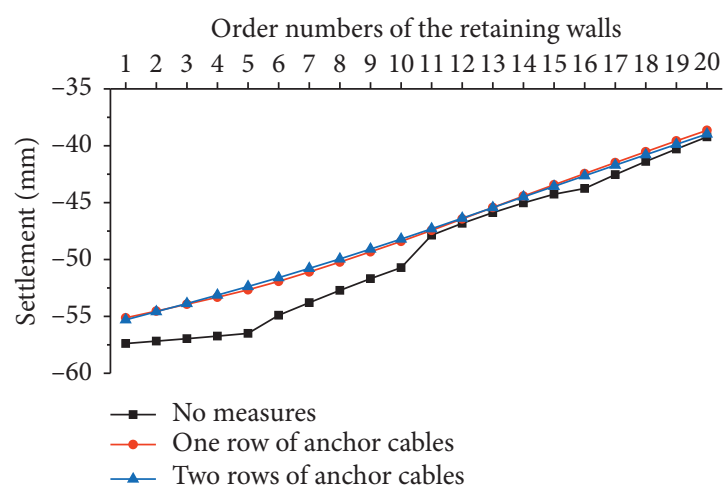

FIGURE 18: Wall bottom final settlement curves in different cases.

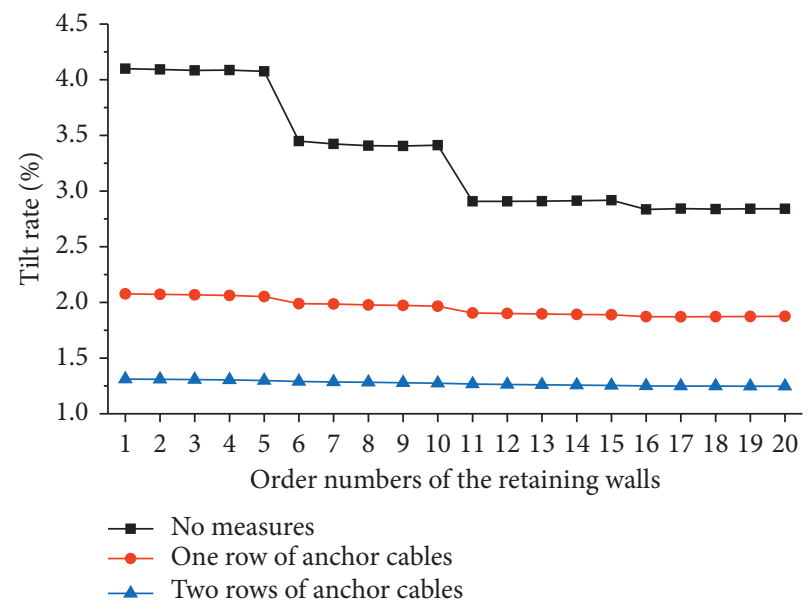

FIgURE 19: Final tilt rate curves of the retaining wall in different cases.

It is also found that the step height difference of the curve after setting the anchor cables is reduced, which indicates that the use of anchor cables with waist beams reduces the deformation difference among the retaining walls and forms a whole to jointly resist the influence of station construction. 


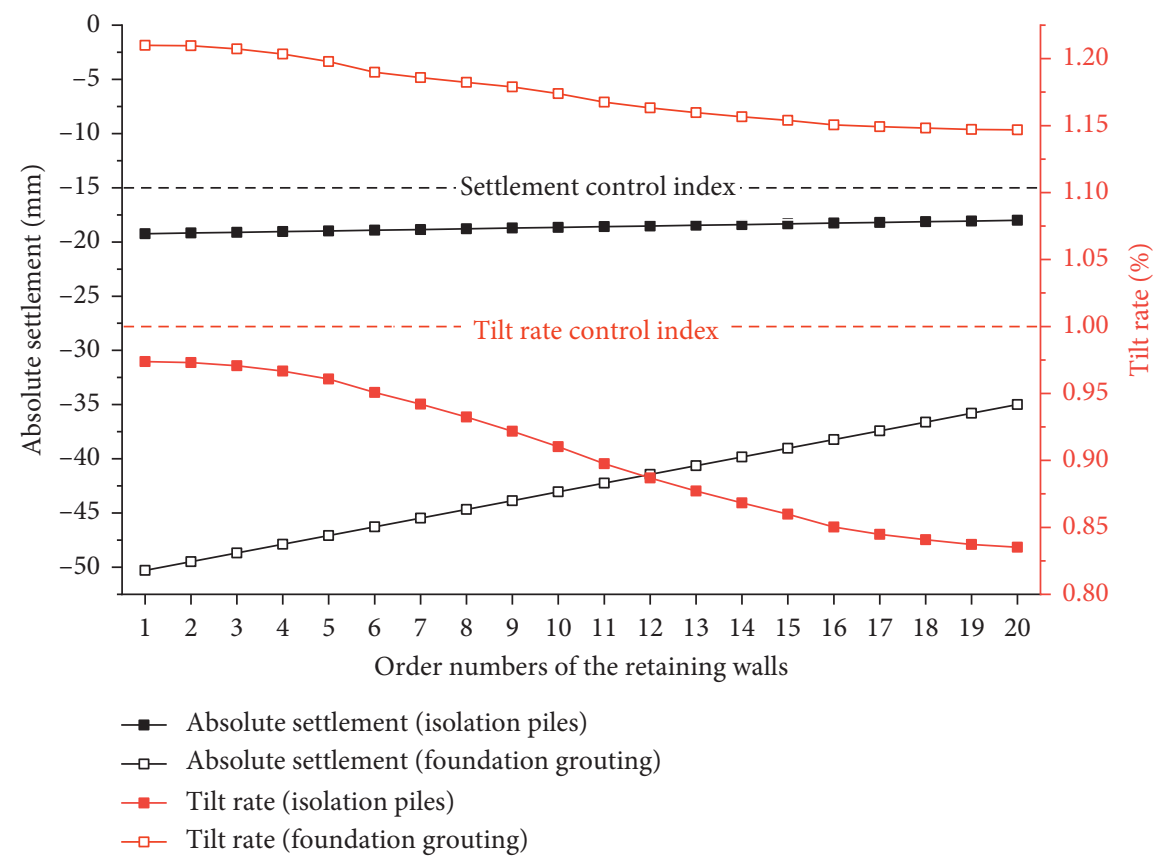

Figure 20: Final absolute settlement and final tilt rate of the retaining wall under the conditions of grouting and isolation piles.

4.3. Comparison of the Protection Effect between Foundation Grouting and Isolation Piles. The absolute settlement of the retaining wall cannot be controlled effectively by means of two rows of anchor cables with waist beams, and the tilt rate still exceeds the index value. Therefore, other means should be combined to control the retaining wall deformation. Grouting and isolation piles are two common means to protect adjacent structures in close construction [26-31]. However, in past engineering practices, the selection of grouting and isolation piles was often blind. Thus, scientific protective means were not selected according to the engineering situation, preventing the expected effect from being achieved or causing material waste. This paper compares and evaluates the protection effect of grouting and isolation piles on the premise of applying two rows of anchor cables with waist beams and analyzes the differences of the protection effect between the two measures.

The final absolute settlement and final tilt rate of the retaining wall under the conditions of grouting and isolation piles are shown in Figure 20.

By comparing settlement and tilt rate curves between the two cases, it is indicated that the control effect of the foundation grouting is not ideal. The maximum settlement of the retaining wall is $50.30 \mathrm{~mm}$, and the maximum tilt rate is $1.21 \%$, exceeding the index value by $235 \%$ and $21 \%$, respectively. Relatively speaking, the control effect of the isolation piles is remarkable. The maximum settlement of the retaining wall is $19.24 \mathrm{~mm}$, and the maximum tilt rate of the retaining wall is $0.97 \%$, which meets the index requirements, but the absolute settlement still exceeds the index value by $28 \%$. Thus, reducing the settlement value of the retaining wall is the most difficult problem in this project, and other means should be combined to control the settlement.
To better explain the reason for the large gap between the protection effects of grouting and those of isolation piles, the stratum settlement cloud maps of the two situations are compared, as shown in Figure 21.

Because the retaining wall foundation is close to the centerline of the main body of the station, the scope of grouting is completely within the scope of the setting tank, and the construction of the station causes the overall settlement of the reinforced soil, which explains why the grouting effect is not significant. In the case of isolation piles, the width of the setting tank decreases obviously, and the impact of the stratum settlement caused by station construction on the retaining wall is weakened. This is because the lower part of the isolation pile goes deep into a stable stratum, and the structure of the isolation pile is stable, which can have an obvious partitioning effect on the transmission of the impacts of construction. In addition, there is no plastic zone in the pile during construction, so the settlement of the retaining wall decreases obviously.

It can be seen from the protection effect of grouting that when grouting reinforcement is carried out around a shallow foundation, if the grouting scope is completely within the construction influence scope, the grouting reinforced body will settle as a whole, and the protection effect on the foundation is not good. A large number of engineering examples have proven that grouting the soils surrounding an excavation space inside a tunnel can effectively control stratum settlement [32-34], so the grouting effect is closely related to the grouting position, and grouting measures are more suitable to solve the settlement problem from the "influence source"; that is, the reasonable grouting range should be the soils around the excavation face. 


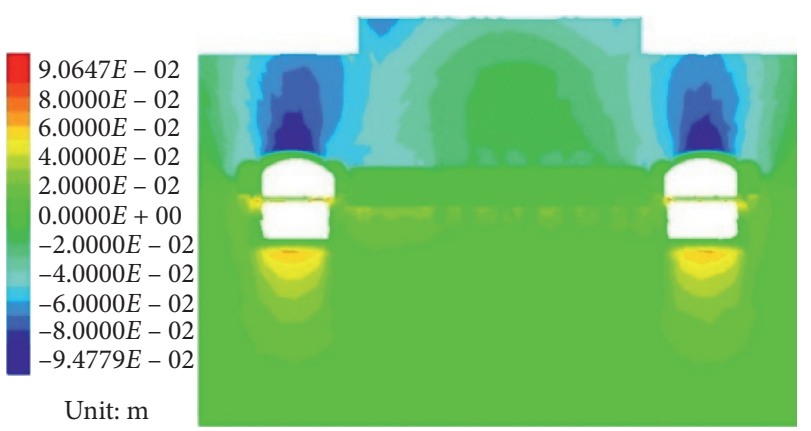

(a)

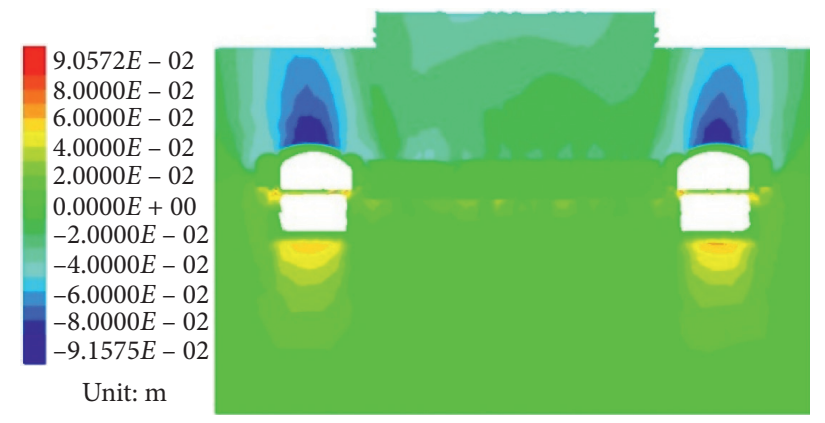

(b)

Figure 21: Comparison of the two stratum settlement cloud maps. (a) Stratum settlement cloud map under grouting conditions. (b) Stratum settlement cloud map under isolation piles conditions.

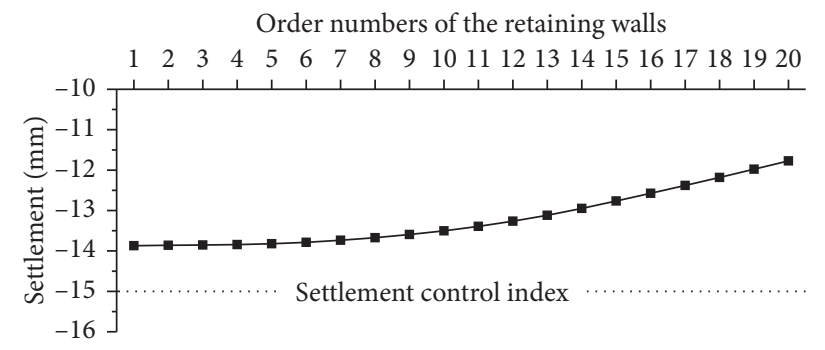

FIGURE 22: Final settlement of each retaining wall.

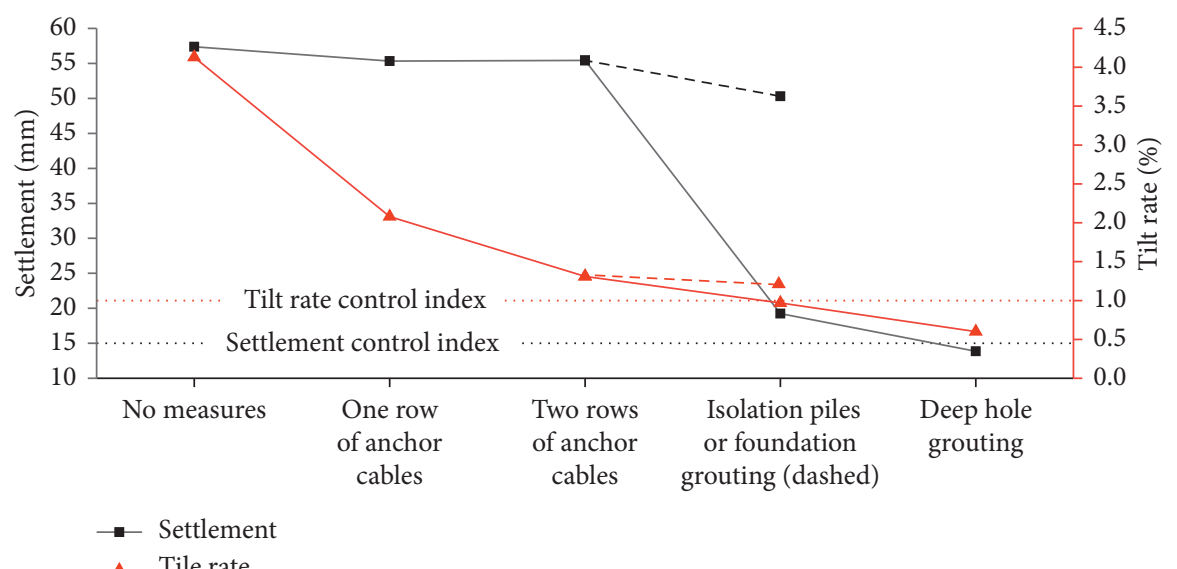

FIGURE 23: Settlement and tilt rate changing curves of the retaining wall.

4.4. Deep Hole Grouting Protection Effect. The differential settlement and tilt rate of the retaining wall meet the index requirements based on the combination of two rows of anchor cables and isolation piles, but the absolute settlement still exceeds the index value. To further reduce the settlement value, deep hole grouting is performed in addition to the aforementioned combination of measures, and the final settlement of each retaining wall is obtained, as shown in Figure 22.

According to the calculation results, the maximum settlement of the retaining wall is $13.87 \mathrm{~mm}$, which meets the index requirement, and the maximum tilt rate of the retaining wall is further reduced to $0.60 \%$.
4.5. Determination of the Final Protection Measure. After analyzing the effect of each control measure, the final protection measure is determined as a combination of two rows of anchor cables, waist beams, isolation piles, and deep hole grouting. To demonstrate the control effect of each measure on the retaining wall deformation, the settlement and tilt rate changing curves of the retaining wall are drawn according to the final deformation of the retaining wall under each measure, as shown in Figure 23 (the measures are gradually accumulated from left to right, and the settlement value is the absolute value).

The joint measures adopted for retaining wall deformation cover the entire transmission of the impacts of the construction: the deep hole grouting aims at the source of 
the influence, the isolation piles aim at the propagation of the influence, and the anchor cables with waist beams aim at the object of the influence. For similar projects with a great difficulty in settlement control, the combination of "source," "propagation," and "object" can effectively protect adjacent structures.

\section{Conclusions}

This paper analyzes the retaining wall deformation under the influence of station construction by a numerical simulation method. Four countermeasures are formulated and their control effects are analyzed. The final protection measures and the protection concept are proposed. The main conclusions are drawn as follows:

(1) The construction of the station has little influence on the differential settlement of adjacent retaining walls, but the affected retaining walls have large absolute settlement and tilt deformation values, forming a trend of "high in the east and low in the west."

(2) Anchor cables with waist beams can effectively control the tilt of the retaining wall, but the tilt rate is still beyond the target in this case. The simulation data show that the control effect of anchor cables on the absolute settlement is not obvious, but this measure has a significant control effect on the tilt of the retaining wall.

(3) The differences in the protection effect between foundation grouting and isolation piles are analyzed. The calculation results show that the foundation grouting control effect is not ideal because of the oversettlement of the reinforced soil, while the control effect of the isolation piles is significant. The tilt rate meets the index requirements when isolation piles is adopted, but the absolute settlement still exceeds the index.

(4) After the analysis, a combination of anchor cables, waist beams, isolation piles, and deep hole grouting is adopted to jointly control the retaining wall deformation. The maximum settlement and the maximum tilt rate of the retaining wall in this case are both less than the deformation index. According to this measure, a concept of joint control aiming at the influences of the "source," "propagation," and "object" is proposed, which can provide a reference for similar projects with a great difficulty in deformation control.

\section{Data Availability}

The data used to support the findings of this study are included within the article.

\section{Conflicts of Interest}

The authors declare that there are no conflicts of interest regarding the publication of this paper.

\section{Acknowledgments}

This research was supported by the National Natural Science Foundation of China (Grant no. 51678033).

\section{References}

[1] D. H. Hu and J. C. Duan, "Risk source analysis and grade division of subway tunnel undercrossing the existing highway subjected to the complicated geological environment," in Proceedings of the International Conference on Power Engineering \& Energy, Environment, pp. 680-684, Shanghai, China, June 2016.

[2] W. Bai, "Study on the deformation law of super highway roadbed crossed by the metro tunnel," in Proceedings of the International Conference on Mechanics and Civil Engineering, vol. 7, pp. 832-835, Wuhan, China, December 2014.

[3] C. Cao, C. Shi, M. Lei, L. Peng, and R. Bai, "Deformation characteristics and countermeasures of shallow and largespan tunnel under-crossing the existing highway in soft soil: a case study," KSCE Journal of Civil Engineering, vol. 22, no. 8, pp. 3170-3181, 2018.

[4] Y. L. Lin and Y. H. Fang, "Settlement behavior of new reinforced earth retaining walls under loading-unloading cycles," in Proceedings of the 2nd International Conference on Civil Engineering and Transportation, vol. 256-259, pp. 215219, October 2012, Applied Mechanics and Materials.

[5] Y. T. Liu and X. Huang, "Numerical analysis of deformation and stability of reinforced high retaining wall," in Proceedings of the 2nd International Conference on Civil, Architectural and Hydraulic Engineering, vol. 405-408, pp. 227-232Applied Mechanics and Materials, Zhuhai, China, July 2013.

[6] Y. Zhao, G. Q. Yang, B. J. Zhang, and P. Lv, "The horizontal deformation study on the geogrid reinforced earth retaining wall," in Proceedings of the 4th Asian Regional Conference on Geosynthetics, pp. 332-335, Shanghai, China, June 2008.

[7] T. Akhlaghi and A. Nikkar, "Numerical analyses of dynamic response of geosynthetic-reinforced soil retaining wall," Geosystem Engineering, vol. 17, no. 2, pp. 142-149, 2014.

[8] K. Y. Jiang, J. Cao, L. Peng, and M. M. Chen, "The deformation character of retaining wall under horizontal earthquake," in Proceedings of the International Conference on Mechanical Engineering and Materials, vol. 152-154, pp. 1443-1447Applied Mechanics and Materials, Melbourne, Australia, January 2012.

[9] Y. L. Lin and G. L. Yang, "Dynamic deformation behavior and life analysis of green reinforced gabion retaining wall," in Proceedings of the 2nd International Conference on Civil Engineering and Transportation, vol. 256-259, pp. 251-255, Guilin, China, October 2012.

[10] S. Nakajima, K. Hong, S. Mulmi, J. Koseki, K. Watanabe, and M. Tateyama, "Study on seismic performance of geogrid reinforced soil retaining walls and deformation characteristics of backfill soil," in Proceedings of the 4th Asian Regional Conference on Geosynthetics, pp. 211-215, Shanghai, China, June 2008.

[11] H.-w. Zhu, L.-k. Yao, and J. Li, "Influence factors on the seismic behavior and deformation modes of gravity retaining walls," Journal of Mountain Science, vol. 16, no. 1, pp. 168-178, 2019.

[12] Z. M. Ghazaly, M. A. Rahim, V. K. Hiung, N. F. Isa, and L. A. Sofri, "The effect of construction stage on the development of retaining wall," in Proceedings of the International 
Conference on Advanced Materials Engineering and Technology, vol. 1835, Taiwan, China, December 2016.

[13] S. Q. Peng, Q. H. Zhao, and Z. Y. Chen, "The relationship between retaining wall deformation and earth pressure in deep excavation," in Proceedings of the 2nd International Conference on Structures and Building Materials, vol. 446-449, pp. 1690-1695Advanced Materials Research, Changsha, China, July 2012.

[14] D. E. L. Ong, C. F. Leung, and Y. K. Chow, "Time-dependent pile behavior due to excavation-induced soil movement in clay," in Proceedings of the 12th Pan-American Conference on Soil Mechanics and Geotechnical Engineering, vol. 2, pp. 2035-2040, Boston, MA, USA, January 2003.

[15] W. H. Ma, C. Y. Yang, H. Peng et al., "Settlement control on retaining wall embankment affected by underneath traversing large-diameter slurry shield tunnels," Journal of Hunan University (Natural Science), vol. 47, no. 3, pp. 44-53, 2020, in Chinese.

[16] X. Y. Liu, "Numerical analysis on construction stability of tunnel crossing underneath existing retaining wall of express highway," Journal of Water Resources and Architectural Engineering, vol. 12, no. 3, pp. 31-35, 2014, in Chinese.

[17] X. Y. Sun, "Analysis and control measures of shallow buried tunnels parallel crossing road retaining wall," Master's thesis, Beijing Municipal Engineering Research Institute, Beijing, China, 2019, in Chinese..

[18] L. Yu, D. Zhang, Q. Fang, L. Cao, T. Xu, and Q. Li, "Surface settlement of subway station construction using pile-beamarch approach," Tunnelling and Underground Space Technology, vol. 90, pp. 340-356, 2019.

[19] B. Li and Z. Z. Wang, "Numerical study on the response of ground movements to construction activities of a metro station using the pile-beam-arch method," Tunnelling and Underground Space Technology, vol. 88, pp. 209-220, 2019.

[20] M. S. Pakbaz, S. Imanzadeh, and K. H. Bagherinia, "Characteristics of diaphragm wall lateral deformations and ground surface settlements: case study in Iran-Ahwaz metro," Tunnelling and Underground Space Technology, vol. 35, pp. 109$121,2013$.

[21] X. Liu, Y. Liu, Z. Yang, and C. He, "Numerical Analysis on the mechanical performance of supporting structures and ground settlement characteristics in construction process of subway station built by pile-beam-arch method," KSCE Journal of Civil Engineering, vol. 21, no. 5, pp. 1690-1705, 2017.

[22] X. Yang and Y. Li, "Research of surface settlement for a single arch long-span subway station using the pipe-roof pre-construction method," Tunnelling and Underground Space Technology, vol. 72, pp. 210-217, 2018.

[23] K. Zhang, J. L. C. Torres, and Z. J. Zang, "Numerical analysis of pipelines settlement induced by tunneling," Advances in Civil Engineering, vol. 2019, Article ID 4761904, 10 pages, 2019.

[24] D. M. Potts, K. Axelsson, L. Grande et al., Guidelines for the Use of Advanced Numerical Analysis, Thomas Telford, London, UK, 2002.

[25] C. S. Desai, M. M. Zaman, J. G. Lightner, and H. J. Siriwardane, "Thin-layer element for interfaces and joints," International Journal for Numerical and Analytical Methods in Geomechanics, vol. 8, pp. 9-43, 1984.

[26] E. Falk, K. Fondazioni, G. Burke, and H. Baker, "Grouting techniques as part of modern urban tunnelling in Europe," in Proceedings of the 3rd International Conference on Grouting and Ground Treatment, vol. 120, pp. 1534-1545, New Orleans, LA, USA, February 2003.
[27] J. Su, Q. Fang, D. L. Zhang, X. Niu, X. Liu, and Y. Jie, "Bridge responses induced by adjacent subway station construction using shallow tunneling method," Advances in Civil Engineering, vol. 2018, Article ID 8918749, 16 pages, 2018.

[28] S. A. Mazek, K. T. Law, and D. T. Lau, "Use of grouting to reduce deformations of an existing tunnel underpassed by another tunnel," in Proceedings of the 3rd International Conference on Grouting and Ground Treatment, vol. 120, pp. 1570-1581, New Orleans, LA, USA, February 2003.

[29] J. Lv, X. Li, Z. Li, and H. Fu, "Numerical simulations of construction of shield tunnel with small clearance to adjacent tunnel without and with isolation pile reinforcement," KSCE Journal of Civil Engineering, vol. 24, no. 1, pp. 295-309, 2020.

[30] J. Tang, J. Y. Liu, and Y. Liu, "Study on the measures of tunnels side-crossing bridge based on sheltering effects of isolation piles," in Proceedings of the 2nd International Conference on Materials Science, Energy Technology and Environmental Engineering, vol. 81, Zhuhai, China, April 2017.

[31] G. Zheng, F. J. Wang, Y. M. Du, Y. Diao, Y. W. Lei, and X. S. Cheng, "The efficiency of the ability of isolation piles to control the deformation of tunnels adjacent to excavations," International Journal of Civil Engineering, vol. 16, no. 10, pp. 1475-1490, 2018.

[32] M. Packer, R. Newman, C. Prangley, and I. Heath, "Permeation grouting and excavation at Victoria station, London," Proceedings of the Institution of Civil Engineers - Geotechnical Engineering, vol. 171, no. 3, pp. 267-281, 2018.

[33] K. Wu and Z. S. Shao, "Effects of pipe roof support and grouting pre-reinforcement on the track settlement," Advances in Civil Engineering, vol. 2018, Article ID 6041305, 9 pages, 2018.

[34] J. J. Li, H. R. Bai, and J. K. Li, "Analysis and control the surface settlement of tunnel excavation," in Proceedings of the 2nd International Conference on Civil Engineering, Architecture and Sustainable Infrastructure, vol. 438-439, pp. 939942, Applied Mechanics and Materials, Zhengzhou, China, July 2013. 